\title{
Dapsone in the treatment of pemphigus vulgaris: adverse effects and its importance as a corticosteroid sparing agent*
}

\author{
Maria Victória Quaresma ${ }^{1}$ \\ Janaína Hezel ${ }^{1}$ \\ Bernard Kawa Kac ${ }^{1}$
}

\author{
Fred Bernardes Filho ${ }^{1}$ \\ Murilo Calvo Peretti ${ }^{1}$ \\ Luna Azulay-Abulafia ${ }^{1,2}$
}

DOI: http:/ / dx.doi.org/10.1590/abd1806-4841.20153408

\begin{abstract}
A bstract: Pemphigus vulgaris is an autoimmune disease characterized by suprabasal blisters with acantholysis, which has a fatal course in a large number of untreated patients. Systemic corticosteroid therapy is considered first-line therapy. Adjuvant treatment with the goal of sparing corticosteroids include, among others, dapsone. This drug is not without side effects and its use requires clinical and laboratory control. We present a patient with PV initially managed with suboptimal dose of prednisone, evolving into drug-induced hepatitis after introduction of dapsone.
\end{abstract}

Keywords: Dapsone; Hepatitis; Pemphigus; Prednisone

\section{INTRODUCTION}

Pemphigus vulgaris (PV) is an autoimmune disease characterized by blisters that may occur in the mucosa or in other areas of the skin. The characteristic histopathological finding of PV are suprabasal blisters with acantholysis. ${ }^{1}$ Glucocorticoids are considered the first-line treatment and are used to reduce the synthesis of autoantibodies. The addition of a second-line therapy is indicated to increase the efficacy and reduce collateral effects of corticotherapy, as well as manage relapses during its gradual withdrawal. ${ }^{2}$ The adjuvant therapy includes azathioprine, methotrexate, cyclophosphamide, mycophenolate mofetil, intravenous immunoglobulin and dapsone. ${ }^{3}$ A patient with PV is presented, initially treated with a subdose of systemic corticotherapy which evolved to drug-induced hepatitis after introduction of dapsone.

\section{CASE REPORT}

Female patient of african-descent, 50 years old, came to the outpatient clinic complaining of a single five-month-old bullous lesion in the oral mucosa, which evolved to erosion and onset of similar cutaneous lesions in other sites. At the examination, ulcerated crusty lesions were found on the face, scalp, trunk, back and upper limbs, some with honey-colored crusts.

She had been previously treated at another clinic with topical antifungals without improvement, followed by prednisone $20 \mathrm{mg}$ / day with slight improvement, which after four months was associated with dapsone $100 \mathrm{mg}$ / day as adjuvant therapy.

At our service, under the diagnostic hypothesis of $\mathrm{PV}$, we performed the histopathological study which showed inflammatory suprabasal acantholytic bullous

Received on 28.01.2014

Approved by the Advisory Board and accepted for publication on 09.04.2014

Work performed at Instituto de Dermatologia Professor Rubem David Azulay - Santa Casa da Misericórdia do Rio de Janeiro (IDPRDA-SCMRJ) - Rio de Janeiro (RJ), Brazil.

Financial Support: None.

Conflict of Interest: None.

Instituto de Dermatologia Professor Rubem David Azulay- Santa Casa da Misericórdia do Rio de Janeiro (IDPRDA-SCMRJ) - Rio de Janeiro (RJ), Brazil.

Universidade do Estado do Rio de Janeiro (UERJ) - Rio de Janeiro (RJ), Brazil.

(C2015 by Anais Brasileiros de Dermatologia 
dermatitis with involvement of pilosebaceous follicle, compatible with PV (Figures 1 and 2). Our option was to increase prednisone to $80 \mathrm{mg} /$ day, with gradual reduction after clinical improvement.

Two weeks after starting therapy with prednisone in its immunosuppression dose and six weeks taking dapsone, the patient reported clinical improvement and denied onset of new lesions. Laboratory control revealed elevation of glutamic oxaloacetic transaminase (GOT $40 \mathrm{U} / \mathrm{L}$ ) glutamic-pyruvic transaminase (GPT $76 \mathrm{U} / \mathrm{L}$ ), gamma-glutamyl transferase (GGT $151 \mathrm{U} / \mathrm{L}$ ) and alkaline phosphatase (ALP $117 \mathrm{U} / \mathrm{L})$, in addition to leukocytosis $(17.300 / \mathrm{mm} 3)$; dapsone was suspended. The following week, she returned complaining of itching, dark urine, acholic feces and jaundice when new control showed significant elevation of aminotransferases (AST 410 U/L, ALT 622

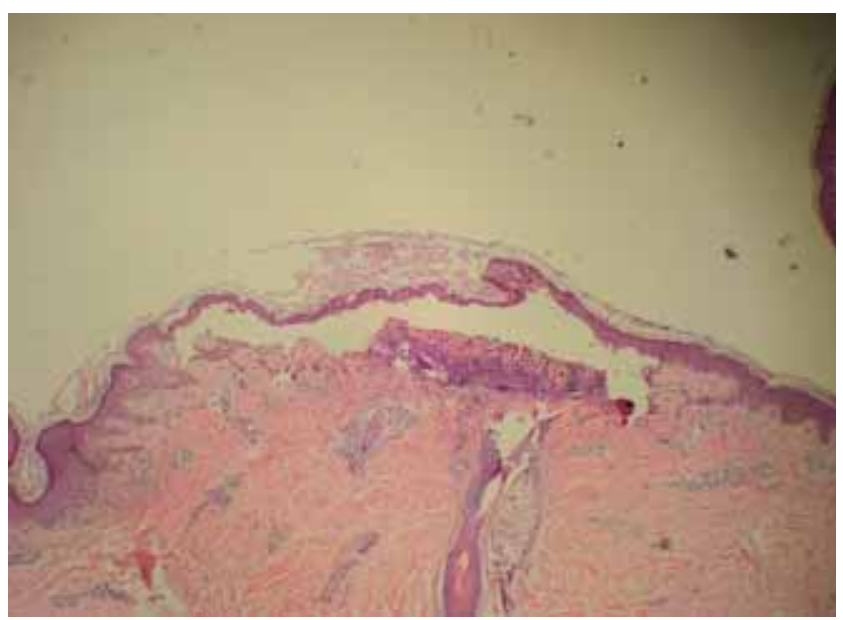

Figure 1: Pemphigus vulgaris. Histopathological examination showing inflammatory suprabasal acantholytic bullous dermatitis with involvement of pilosebaceous follicle (Hematoxylin-eosin, 40x)

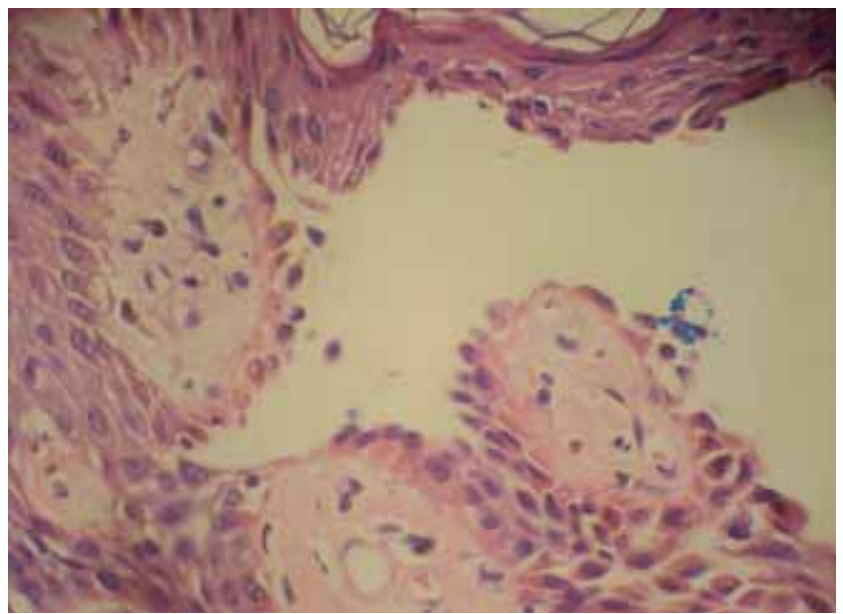

FIGURE 2: Pemphigus vulgaris. Detail of histopathological examination: formation of suprabasal acantholytic blister (Hematoxylin-eosin, 100x)
U/L), bile canalicular enzymes (ALP 361 U/L GGT $1265 \mathrm{U} / \mathrm{L}$ ), direct bilirubin (BD $4.0 \mathrm{mg} / \mathrm{dl}$ ) and indirect bilirubin (BI $3.7 \mathrm{mg} / \mathrm{dl})$. She was then hospitalized and serology for viral hepatitis was requested, which resulted negative. A total abdominal ultrasonography revealed no abnormalities. The blood levels of liver enzymes and bilirubin during dapsone use and after withdrawal are shown in figures 3 and 4 .

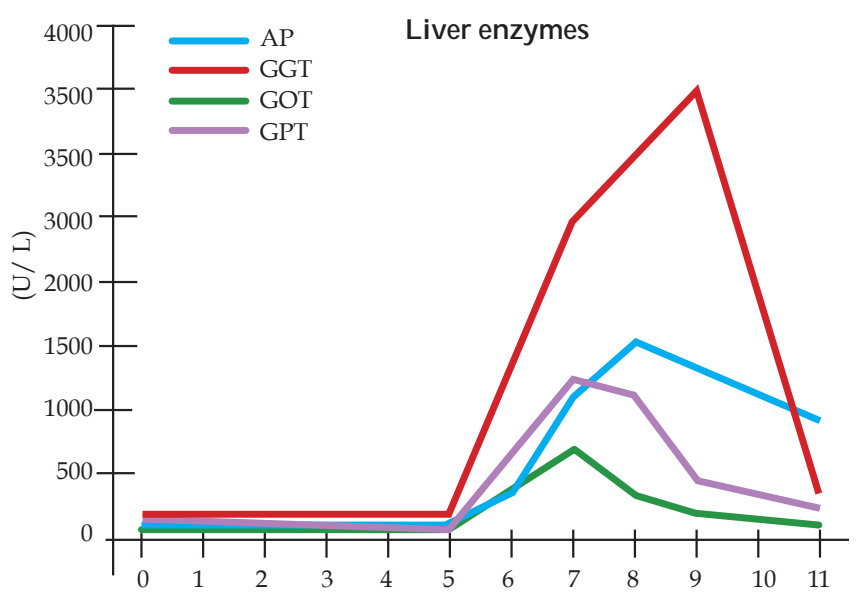

Weeks of case progression after use of dapsone: (The drug was introduced in week 0 and suspended in week 5)

AP - alkaline phosphatase; G G T - gamma glutamyl transferase; G OT - glutamic oxaloacetic transaminase; G PT - glutamic pyruvic transaminase

Figure 3: Blood levels of liver enzymes during use of dapsone and after withdrawal

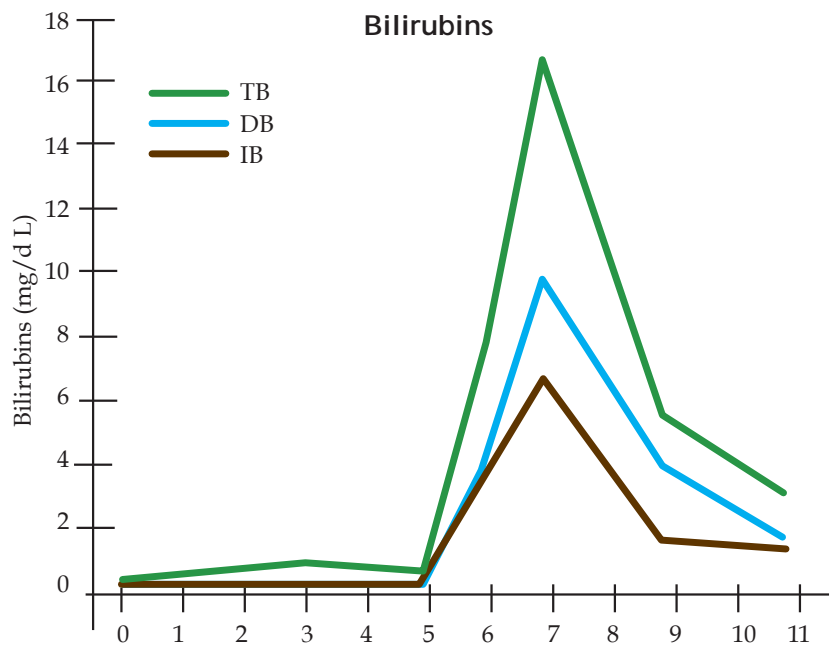

Weeks of case progression after use of dapsone: (The drug was introduced in week 0 and suspended in week 5)

TB - total bilirubins; D B - direct (conjugated) bilirubin; IB - indirect (unconjugated) bilirubin

Figure 4: Blood levels of bilirubins during use of dapsone and after withdrawal 


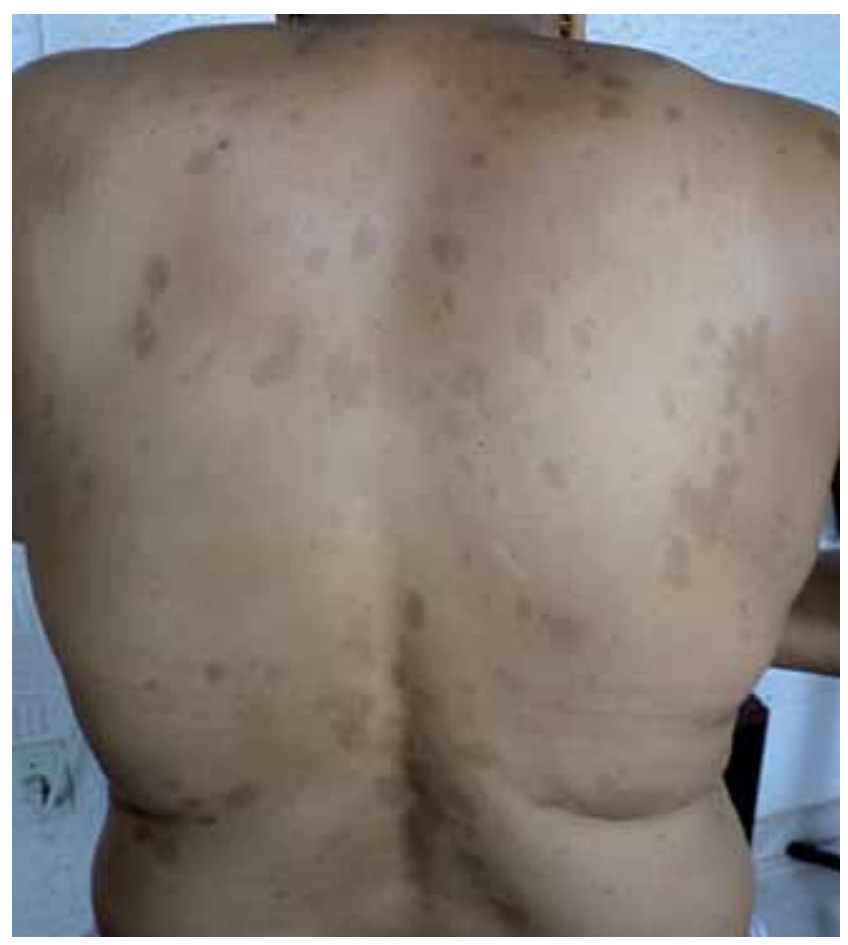

Figure 5: Patient with pemphigus vulgaris after treatment. Residual hyperchromic macules on the back

Thirteen weeks after suspension of dapsone, with decreasing doses of corticotherapy until the current dose of prednisone $30 \mathrm{mg} /$ day, the patient presented clinical improvement: only small ulcerated crusty areas on the scalp and absence of new lesions. Residual hyperchromic macules were also noted on the face, trunk, back and upper limbs (Figure 5).

\section{DISAUSSION}

Systemic corticotherapy is essential in the management of pemphiguses. For PV, the initial dose is $1-2 \mathrm{mg} / \mathrm{kg} /$ day. The reduction of the corticoid must be started after complete remission of the cutaneous condition and about 1-2 weeks without the onset of new lesions. The dose is reduced by $10 \mathrm{mg} /$ week until $30 \mathrm{mg} /$ day is achieved and following that the reduction should be $5-10 \mathrm{mg} /$ month, obtaining the dose of $10 \mathrm{mg} /$ day. From this dose, withdrawal occurs with decrease of $2.5 \mathrm{mg}$ every 1-2 months according to clinical course of the disease. Treatment may be suspended after 1 year of low daily doses on alternate days, without the onset of new lesions. ${ }^{4}$
For PV, dapsone is appropriate as an adjuvant to corticotherapy in the maintenance phase of the disease. 5,6 Clinical improvement, in general, happens in 2-3 weeks from the beginning of treatment, leading to sharp reduction or even corticoid suspension within 1-3 months. Dapsone acts by diminishing paraminobenzoic acid to folic acid conversion, preventing the migration of polymorphonuclear cells by inhibiting lysosomal enzymatic activity, interfering with the leucocitary cytotoxic system or preventing cellular response to chemotactic stimuli. ${ }^{7}$ There is evidence of dapsone efficacy $(71 \%$ to $83.3 \%)$ in the adjuvant treatment with topical or oral corticosteroids in patients with pemphiguses. ${ }^{8}$

Collateral effects of dapsone may be classified into idiosyncratic and dose-dependent. Among the idiosyncratic ones there is the rare dapsone hypersensitivity syndrome, characterized by fever, lymphadenopathy, erythematous cutaneous eruptions and occasionally hepatic involvement. Dose-dependent effects encompass hemolysis and methemoglobinemia. ${ }^{7}$ A study in tertiary centers showed that this drug was the most common cause of acquired methemoglobinemia, responsible for $42 \%$ of the cases. ${ }^{9}$ Methemoglobinemia is not caused by the drug itself, but by its metabolite, hydroxylamine. ${ }^{8}$

A link between development of drug-induced hepatitis and dapsone has been suspected. Complete blood count must be monitored monthly in the first six months of use and renal and liver function must be verified quarterly for toxicity research. ${ }^{2}$ The interval between the initiation of treatment and the onset of hepatitis varies from two to seven weeks. Hepatocellular and cholestatic reactions may occur, the latest being the most common mechanism of the lesion and characterized by the elevation of alkaline phosphatase and transaminases. The hepatocellular lesion is characterized by elevation of transaminases and the lesion mechanism occurs by hepatotoxicity and hypersensitivity reaction. ${ }^{10}$ The patient of the present case developed drug-induced hepatitis with cholestatic pattern by dapsone, due to the time she started using it, laboratory alterations found and exclusion of other hepatopathology causes.

Therefore, in this clinical case, the use of dapsone as corticoid-sparing drug is reported for PV, a disease of significant morbimortality, and the occurrence of drug-induced hepatitis by this drug, emphasizing the relevance of laboratory control during its use, aiming to prevent undesirable collateral effects, deleterious if not detected early. $]$ 


\section{REFERENCES}

1. Enk $\mathrm{AH}, \mathrm{Knop} \mathrm{J}$. Mycophenolate is effective in the treatment of pemphigus vulgaris. Arch Dermatol. 1999;135:54-6.

2. Han A. A practical approach to treating autoimmune bullous disorders with systemic medications. J Clin Aesthet Dermatol. 2009;2:19-28.

3. Scully C, Challacombe SJ. Pemphigus vulgaris: update on etiopathogenesis, oral manifestations, and management. Crit Rev Oral Biol Med. 2002;13:397-408.

4. Cunha PR, Barraviera SR. Autoimmune bullous dermatoses. An Bras Dermatol. 2009;84:111-24.

5. Heaphy MR, Albrecht J, Werth VP. Dapsone as a glucocorticoid-sparing agent in maintenance-phase pemphigus vulgaris. Arch Dermatol. 2005;141:699-702.

6. Werth VP, Fivenson D, Pandya AG, Chen D, Rico MJ, Albrecht J, et al. Multicenter randomized, double-blind, placebo-controlled, clinical trial of dapsone as a glucocorticoid-sparing agent in maintenance-phase pemphigus vulgaris. Arch Dermatol. 2008;144:25-32

7. Bernabé DG, Moraes NP, Correia CM, Furuse CF, Crivelini MM. Tratamento do pênfigo vulgar oral com corticosteroides tópico e sistêmico associados a dapsona e pentoxifilina. Rev Odontol UNESP. 2005;34:49-55.

8. Ciarrocca KN, Greenberg MS. A retrospective study of the management of oral mucous membrane pemphigoid with dapsone. Oral Surg Oral Med Oral Pathol Oral Radiol Endod. 1999;88:159-63.

9. Ash-Bernal R, Wise R, Wright SM. Acquired methemoglobinemia: a retrospective series of 138 cases at 2 teaching hospitals. Medicine (Baltimore). 2004;83:265-73.

10. Agrawal S, Agarwalla A. Dapsone hypersensitivity syndrome: a clinicoepidemiological review. J Dermatol. 2005;32:883-9.
M AILING ADDRESS:

M aria Victória Q uaresma

A lameda Itu, 1030/ 9B

Jardim Paulista

01421-001 - São Paulo - SP

Brazil

E-mail: mavi@mavictoria.com.br

How to dite this article: Quaresma MV, Bernardes-Filho F, Hezel J, Peretti MC, Kac BK, Azulay-Abulafia L. Dapsone in the treatment of pemphigus vulgaris: adverse effects and their importance as a corticosteroid sparing. An Bras Dermatol. 2015;90 (3 Suppl 1): S51-4. 